\title{
Correction to: Video-Based Coaching: Current Status and Role in Surgical Practice (Part 1) From the Society for Surgery of the Alimentary Tract, Health Care Quality and Outcomes Committee
}

\author{
Deborah S. Keller ${ }^{1}$ (D) Emily R. Winslow ${ }^{2} \cdot$ Joel E. Goldberg ${ }^{3} \cdot$ Vanita Ahuja $^{4}$
}

Published online: 20 January 2022

(c) The Society for Surgery of the Alimentary Tract 2022

\section{Correction to: Journal of Gastrointestinal Surgery}

https://doi.org/10.1007/s11605-021-05102-1

Changes were made to the figure legends of this paper. The paper has been updated.

Publisher's Note Springer Nature remains neutral with regard to jurisdictional claims in published maps and institutional affiliations.

The original article can be found online at https://doi.org/10.1007/ s11605-021-05102-1

Deborah S. Keller

debby_keller@hotmail.com

1 Division of Colorectal Surgery, Department of Surgery,

University of California At Davis Medical Center,

Sacramento, CA, USA

2 Division of Hepatopancreaticobiliary Surgery, Department of Surgery, MedStar Georgetown University Hospital, Washington, DC, USA

3 Division of General and Gastrointestinal Surgery, Brigham and Women's Hospital, Boston, MA, USA

4 Department of Surgery, Yale University Medical Center, New Haven, CT, USA 